\title{
Contribution of Guglielmi Detachable Coil Technique in the Treatment of Intracranial Aneurysms
}

\author{
Fernando ViÑUela, Gary DUCKWILER, Y. Pierre GoBIN, and Guido GuGlielmi
}

Division of Interventional Neuroradiology, University of California Los Angeles School of Medicine and Medical Center, Los Angeles, California, U.S.A.

\section{Introduction}

The Guglielmi detachable coil (GDC) technology for embolization of intracranial aneurysms was developed by Guglielmi et al. at University of California Los Angeles (UCLA) Medical Center and first described in the literature in $1991 .^{1,2)}$ Since then, this technology has become the endovascular gold standard to be applied in ruptured and unruptured intracranial aneurysms. ${ }^{3,8.9)}$ The new of balloons, ${ }^{4]}$ pushable microcoils, ${ }^{6)}$ and liquid agents ${ }^{5}$ to occlude intracranial aneurysms lacked the sufficient control and predictability to make them safe when used in acutely ruptured aneurysms.

The GDC technology consists in the endovascular catheterization of an intracranial aneurysm with a microcatheter and occlusion of it by delivering detachable platinum coils. The platinum microcoil is soldered to a stainless guidewire that permits the accurate delivery of the coil, withdrawal and repositioning until the coil is safely anchored in the aneurysm. The platinum coil is detached by using an electrical current of $1 \mathrm{~mA}$. Several coils can be delivered into the aneurysm through the same microcatheter until the aneurysm is densely packed (Fig. 1). The most important mechanical factor to achieve a complete and permanent aneurysm occlusion is the density of the coils and not the development of an intra-aneurysmal clot by electrothrombosis.

There is a variety of platinum coils with different diameters and lengths and they are chosen depending on the size of the aneurysm, the size of its neck, and its anatomical integrity (ruptured vs. unruptured). The recent development of special soft coils has increased the capacity of dense aneurysm packing while decreasing the possibility of aneurysm perforation in cases of embolization of super-hot aneurysms (treated within 24 hours of rupturing). This type of coil is very delicate and fills the interstices of the regular coils without displacing them or the tip of the microcatheter.

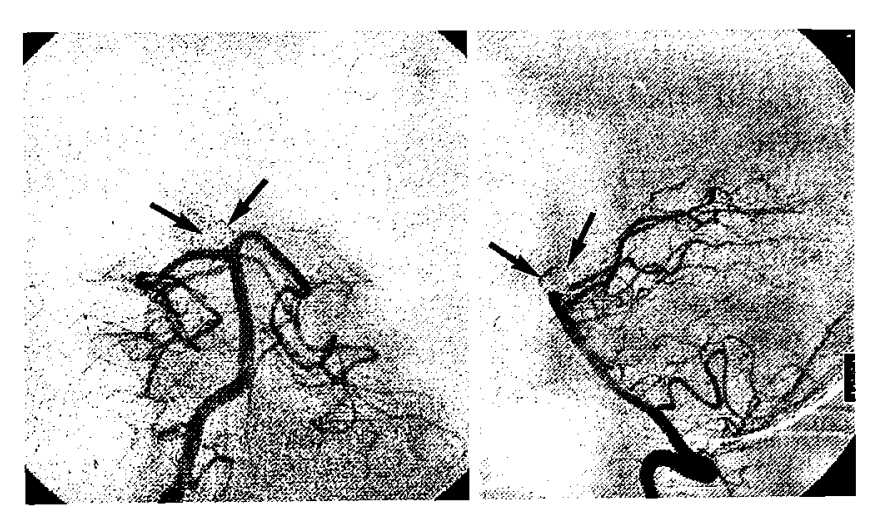

Fig. 1 Dense Guglielmi detachable coil (GDC) packing in basilar tip aneurysm. One-year follow-up anteroposterior (left) and lateral (right) vertebral angiograms show complete basilar tip aneurysm occlusion (arrows) with densely packed GDC coils.

\section{Technical considerations}

The Division of Interventional Neuroradiology, at UCLA Medical Center has been involved in the GDC embolization of 374 patients harboring 415 aneurysms, from April 1990 to September 1997. At the beginning of this clinical experience, only high risk surgical aneurysms were embolized with GDC coils. This referral pattern is reflected in the spectrum of patients and aneurysms described in this series. The most common reasons for neurosurgical exclusion included difficult anatomical location, large size of the aneurysm, failed previous surgical exploration, and patient's poor medical and neurological conditions.

After Food and Drug Administration (FDA) approval of GDC technology in June 1995, the indication of the GDC embolization of intracranial aneurysms has broadened and now incorporates aneurysms that can also be treated by neurosurgical techniques. 

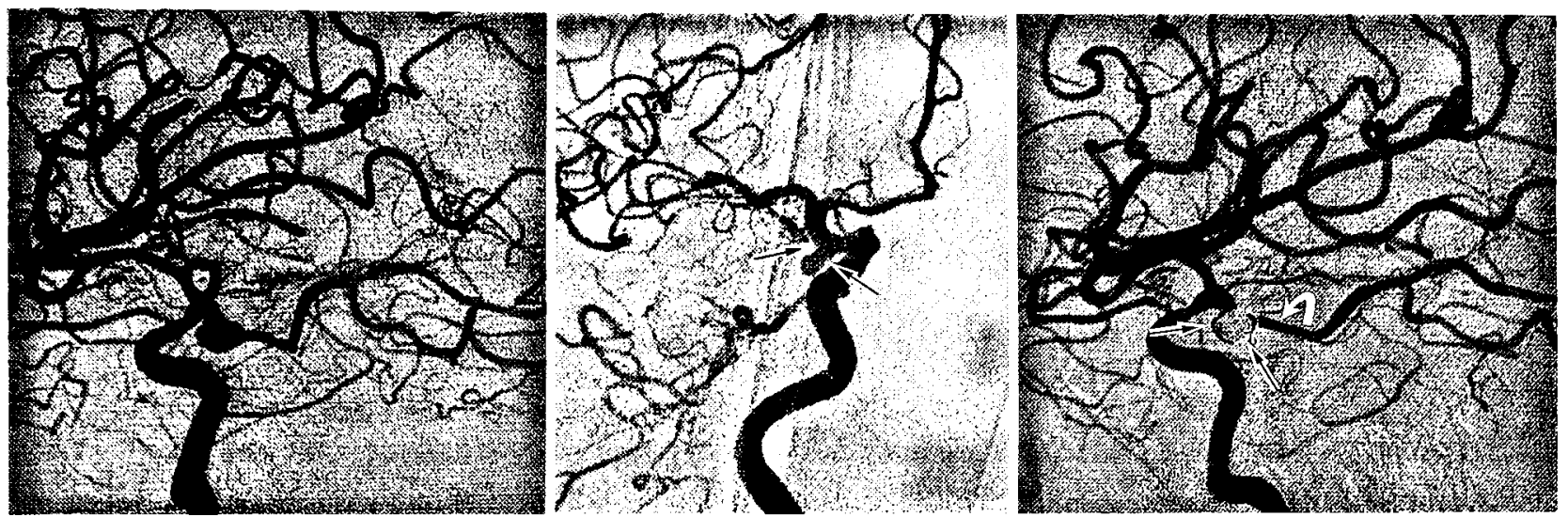

Fig. 2 Appropriate angiographic evaluation of neck of aneurysm. Lateral view of right internal carotid angiogram (left) shows a posterior communicating artery aneurysm totally superimposed on the ostium of a large posterior cerebral artery. Anteroposterior oblique view (center) separates the neck of the aneurysm (arrow) from the ostium of the posterior cerebral artery and lumen of the internal carotid artery. Postembolization internal carotid angiogram (right) shows complete aneurysm occlusion with Guglielmi detachable coil (arrows) and preservation of the lumen of the posterior cerebral artery (curved arrow).

The technical description of the GDC system has been well documented in the neurosurgical literature. ${ }^{1,2)}$ There are some technical points that need to be emphasized:

General anesthesia is preferred to local anesthesia in most neurointerventional centers. It allows a better control of patient's cardiorespiratory condition, a perfect picture of the aneurysm in road mapping imaging, and it permits a better medical/surgical management of endovascular technical complications such as aneurysm perforation or untoward intracranial thromboembolism.

Most patients are embolized under system heparinization (intravenous bolus injection of 5000 $U$ of heparin followed by intravenous bolus injection of $1000 \mathrm{U} / \mathrm{hr}$ ). Systemic heparinization decreases the rate of intracranial embolic complications arising from the coaxial systems or from emboli arising from the embolized aneurysm (particularly wide neck or large aneurysms). Systemic heparinization may be used even in super-hot aneurysms (rupture less than $24 \mathrm{hrs}$ ), as soon as the dome and body of the aneurysm has been occluded with GDCs. The systemic heparinization is reversed with protamine injection ( $10 \mathrm{mg} / 1000 \mathrm{U}$ of heparin) in most patients. In those cases in which there is an increased probability of thromboembolic complications, systemic heparinization may be maintained longer and be supplemented with aspirin and/or ticloid per os.

It is indispensable to identify the neck of the aneurysm by angiographic means in all cases. The GDC embolization in an aneurysm without appropri- ate visualization of its neck increases the probability of untoward embolic complications, local occlusion of the parent artery or deep perforators (Fig. 2). This is particularly true in basilar tip, middle cerebral, and anterior communicating artery aneurysms. A three-dimensional (3-D) computed tomography (CT) angiography may provide valid supplementary information on the relationship of an aneurysm with local vascular structures.

A dense GDC packing of the aneurysm needs to be obtained to eliminate acute aneurysm rebleeding and to decrease long-term aneurysm recanalization. A loose GDC packing does not protect the aneurysm from rebleeding in the acute phase of subarachnoid hemorrhage. Our experience related to long-term angiographic follow-ups of aneurysms treated with GDCs shows that in those aneurysms in which a dense packing has been obtained in the aneurysm inflow zone, a complete and permanent aneurysm occlusion can be obtained. This can be easily achieved in small neck aneurysms (less than $5 \mathrm{~mm}$ in diameter) and it is more difficult to achieve in wide neck aneurysms (Fig. 3). The balloon-assisted technology of GDC embolization described by Moret et al. ${ }^{7}$ appears to improve anatomical results in wide neck aneurysms.

At least 6 months and 1 year angiographic followups need to be obtained to document long-term anatomical results. The presence of an aneurysm residual neck in some cases may be treated conservatively (small residual neck anatomically unchanged), by further GDC embolization or by neurosurgical 


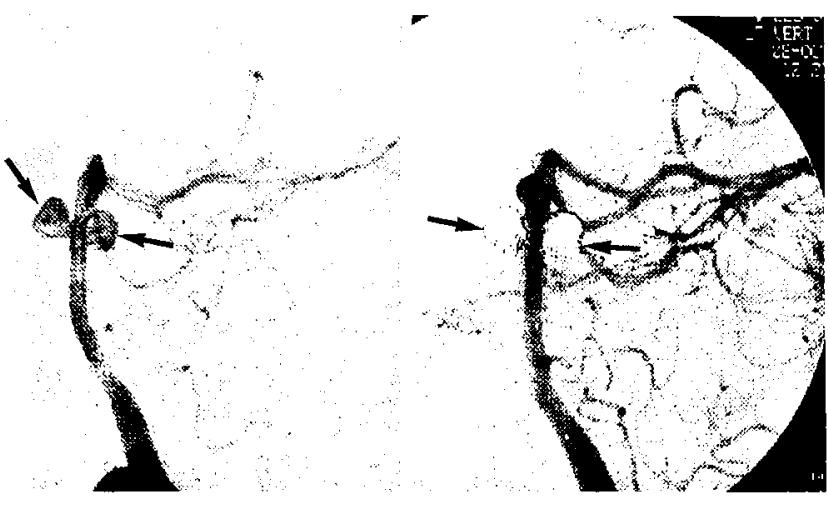

Fig. 3 Guglielmi detachable coil (GDC) embolization in small neck aneurysms. Lateral view of vertebral angiogram (left) shows two basilar trunk, small, saccular "kissing" aneurysms (arrows). Postembolization vertebral angiogram (right) shows complete GDC occlusion of the two aneurysms (arrows), with preservation of the lumen of the basilar artery. The patient remained neurologically intact.

techniques.

\section{UCLA Clinical Experience}

A total of 374 patients harboring 415 aneurysms were treated at UCLA Medical Center from April 1990 to September 1997. $220(60.7 \%)$ were in the an-
Table 1 Age distribution

\begin{tabular}{ccc}
$\begin{array}{c}\text { Age } \\
\text { (yrs) }\end{array}$ & $\begin{array}{c}\text { Anterior } \\
\text { circulation }\end{array}$ & $\begin{array}{c}\text { Posterior } \\
\text { circulation }\end{array}$ \\
\hline$<30$ & $5 \%$ & $4.7 \%$ \\
$31-50$ & $42.5 \%$ & $41.4 \%$ \\
$51-70$ & $38.5 \%$ & $44.5 \%$ \\
$71-90$ & $14 \%$ & $9.4 \%$ \\
\hline
\end{tabular}

Table 2 Most common clinical presentation

\begin{tabular}{lcc} 
Clinical presentation & $\begin{array}{c}\text { Anterior } \\
\text { circulation }\end{array}$ & $\begin{array}{c}\text { Posterior } \\
\text { circulation }\end{array}$ \\
\hline Acute SAH & $40.3 \%$ & $\mathbf{5 5 . 3} \%$ \\
Non-acute SAH & $10.7 \%$ & $16.3 \%$ \\
Incidental & $35.7 \%$ & $16.9 \%$ \\
Mass effect & $13.3 \%$ & $11.5 \%$
\end{tabular}

SAH: subarachnoid hemorrhage.

terior circulation and 146 (39.3\%) were in the posterior circulation. The relatively high incidence of aneurysms in the posterior circulation when compared with the neurosurgical series is explained by the especial referral pattern (high risk neurosurgical aneurysms) that we had before the GDC technology was FDA approved.

The age distribution in anterior and posterior circulation aneurysms is detailed on Table 1 . Seventy
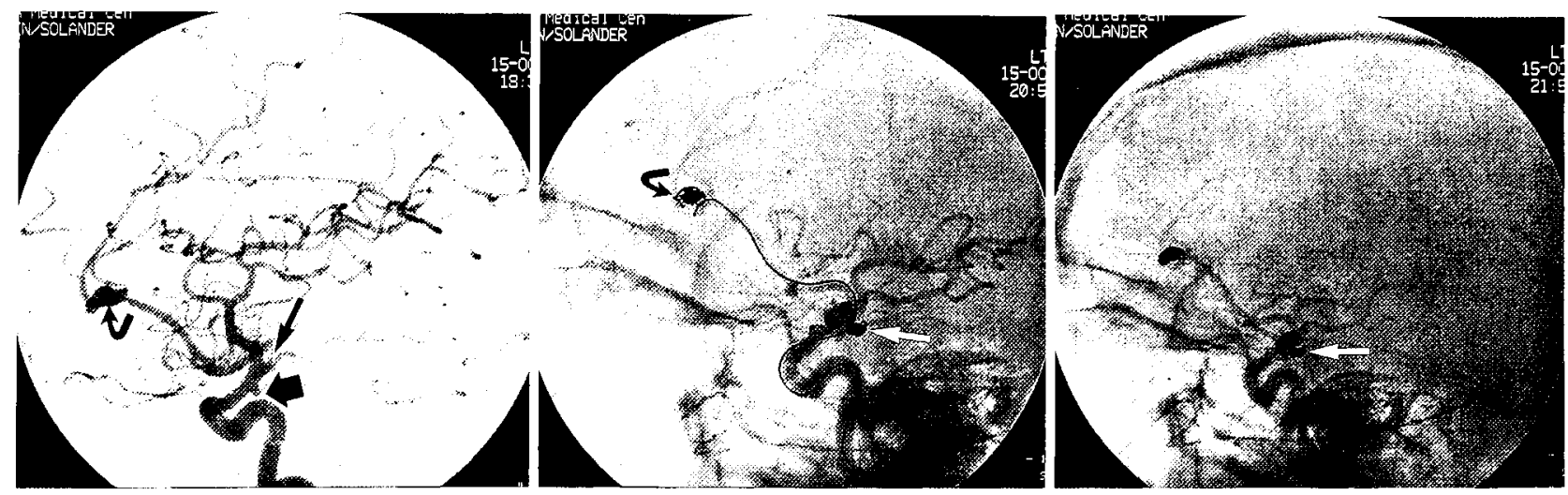

Fig. 4 Guglielmi detachable coil (GDC) embolization in multiple aneurysms. Lateral internal carotid angiogram (left) shows a posterior communicating artery infundibulum (thick arrow), an anterior choroidal artery aneurysm (arrow), and a peripheral anterior communicating artery aneurysm (curved arrow). Non-subtracted lateral internal carotid angiogram (center) shows complete GDC occlusion of the anterior choroidal artery aneurysm (arrow) and active embolization of the anterior cerebral artery aneurysm (curved arrow). Immediate postembolization angiogram (right) shows total GDC occlusion of the two aneurysms (arrows) with preservation of the normal intracranial circulation. A total of five aneurysms were occluded in this patient, in one single session. 
percent of patients were female and $30 \%$ were males.

The patients clinical presentation are described on Table 2. In patients with acute subarachnoid hemorrhage, the GDC embolization of the ruptured aneurysm was performed as an emergency, as soon as the patient was stable enough to be transported to the neuro-angiography suite. This therapeutic strategy eliminates the risk of aneurysm rebleeding and allows an aggressive medical/endovascular therapy of symptomatic arterial vasospasm. In cases of multiple aneurysms, the ruptured aneurysm is occluded first, followed by endovascular occlusion of the remaining incidental aneurysms in the same therapeutic session (Fig. 4).

In the anterior circulation, the most common aneurysms were carotid ophthalmic/paraophthalmic (19.5\%), anterior communicating (13.2\%), posterior communicating/anterior choroidal $(9.6 \%)$, middle cerebral $(7.4 \%)$, and intracavernous arteries $(3.3 \%)$. In the posterior circulation the most common aneurysm was the basilar tip aneurysm (18.5\%), followed by the vertebral/vertebrobasilar junction $(5.5 \%)$, superior cerebellar $(3.8 \%)$, and posterior cerebral artery $(2.1 \%)$ aneurysms.

The aneurysm size is detailed on Table 3. Note is made that in the anterior circulation $41 \%$ of aneurysms were large or giant and in the posterior circulation $47.6 \%$ of aneurysms were large or giant.

The size of the aneurysm neck is detailed on Table 4. The increased incidence of fusiform aneurysms in the posterior circulation relates to the relatively high frequency of symptomatic fusiform aneurysms in the vertebral and posterior cerebral arteries (Fig. 5). Some of these fusiform aneurysms were dissecting in nature and presented with an acute subarachnoid hemorrhage. The GDC technique is especially useful in vertebral artery dissecting aneurysms. A complete GDC aneurysm occlusion and trapping can be obtained with very low morbidity.

Table 5 documents the reasons why these aneurysms were excluded from neurosurgical intervention. Posterior fossa and in particular acutely ruptured basilar tip aneurysms were predominant in the early phases of clinical utilization of the GDC technique. The endosaccular occlusion of the aneurysm decreases the possibility of occlusion of perforators or the ostium of the posterior cerebral ar-

Table 3 Aneurysm size

\begin{tabular}{ccc}
\hline Size & $\begin{array}{c}\text { Anterior } \\
\text { circulation }\end{array}$ & $\begin{array}{c}\text { Posterior } \\
\text { circulation }\end{array}$ \\
\hline Small & $58.3 \%$ & $52.4 \%$ \\
Large & $29.4 \%$ & $28.7 \%$ \\
Giant & $12.3 \%$ & $18.9 \%$ \\
\hline
\end{tabular}

Table 4 Aneurysm neck size

\begin{tabular}{lcc}
\hline \multicolumn{1}{c}{ Size } & $\begin{array}{c}\text { Anterior } \\
\text { circulation }\end{array}$ & $\begin{array}{c}\text { Posterior } \\
\text { circulation }\end{array}$ \\
\hline Small & $37.3 \%$ & $31.2 \%$ \\
Wide & $60.3 \%$ & $53.6 \%$ \\
Fusiform & $2.4 \%$ & $15.2 \%$ \\
\hline
\end{tabular}

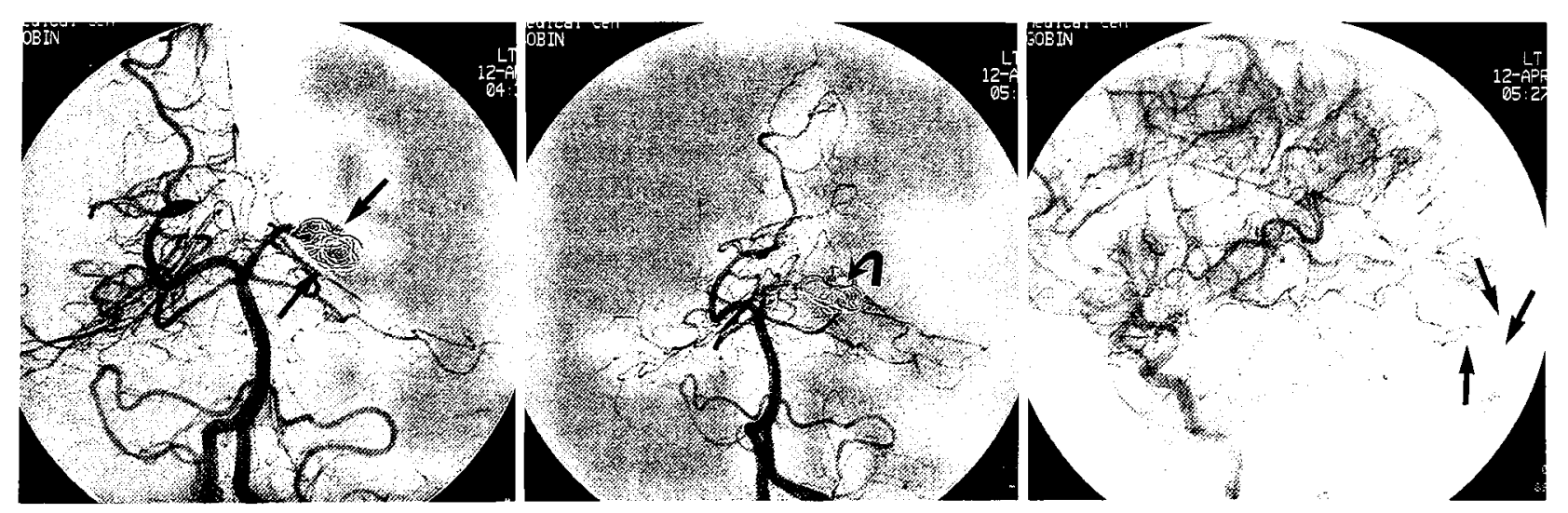

Fig. 5 Guglielmi detachable coil (GDC) embolization of posterior cerebral artery fusiform aneurysm. Anteroposterior view of left vertebral angiogram (left) shows partial GDC embolization of a fusiform left posterior cerebral artery aneurysm (arrows). Immediate postembolization vertebral angiogram (center) shows total GDC occlusion of the aneurysm (curved arrow) and lumen of the left posterior cerebral artery. Lateral view of left internal carotid angiogram (right) shows leptomeningeal collaterals (arrows) supplying the left occipital pole. The patient remained neurologically intact. 
Table 5 Exclusion from surgery

\begin{tabular}{lcc}
\hline Reason & $\begin{array}{c}\text { Anterior } \\
\text { circulation }\end{array}$ & $\begin{array}{c}\text { Posterior } \\
\text { circulation }\end{array}$ \\
\hline $\begin{array}{c}\text { Anticipated surgical } \\
\text { difficulty }\end{array}$ & $53.4 \%$ & $66.5 \%$ \\
$\begin{array}{l}\text { Surgical failure } \\
\text { Patient refuses }\end{array}$ & $16.3 \%$ & $9.6 \%$ \\
$\begin{array}{c}\text { surgery } \\
\text { Poor neurological } \\
\text { status }\end{array}$ & $11.8 \%$ & $3.3 \%$ \\
Poor medical status & $11.6 \%$ & $13.2 \%$ \\
\hline
\end{tabular}

Table 6 Anatomical results

\begin{tabular}{|c|c|c|c|c|}
\hline Aneurysm & Complete & $\begin{array}{l}\text { Residual } \\
\text { small }\end{array}$ & $\begin{array}{c}\text { Residual } \\
\text { large }\end{array}$ & Attempt \\
\hline \multicolumn{5}{|l|}{ Anterior circulation: } \\
\hline $\begin{array}{l}\text { Small aneurysm/ } \\
\text { small neck }\end{array}$ & $81.2 \%$ & $16.8 \%$ & $0 \%$ & $2 \%$ \\
\hline $\begin{array}{l}\text { Small aneurysm/ } \\
\text { wide neck }\end{array}$ & $42 \%$ & $40.5 \%$ & $0 \%$ & $17.5 \%$ \\
\hline Large aneurysm & $45.8 \%$ & $50 \%$ & $4.2 \%$ & $0 \%$ \\
\hline Giant aneurysm & $16.6 \%$ & $55.7 \%$ & $27.7 \%$ & $0 \%$ \\
\hline \multicolumn{5}{|c|}{ Posterior circulation: } \\
\hline $\begin{array}{l}\text { Small aneurysm/ } \\
\text { small neck }\end{array}$ & $83.8 \%$ & $16.2 \%$ & $0 \%$ & $0 \%$ \\
\hline $\begin{array}{l}\text { Small aneurysm/ } \\
\text { wide neck }\end{array}$ & $48.26 \%$ & $44.8 \%$ & $3.54 \%$ & $3.4 \%$ \\
\hline Large aneurysm & $47.8 \%$ & $39.17 \%$ & $4.34 \%$ & $8.69 \%$ \\
\hline Giant aneurysm & $35 \%$ & $48.3 \%$ & $12.5 \%$ & $4.2 \%$ \\
\hline
\end{tabular}

tery.

Table 6 details anatomical results in anterior and posterior circulations, in relation to the size of the aneurysm and the width of its neck. The best anatomical results are not related to the topography of the aneurysm but to its size and the size of its neck. More than $80 \%$ of small aneurysms with a small neck were totally obliterated in either circulation. This anatomical results were only valid if no aneurysm residuum was observed in the angiographic view that showed the aneurysm neck at its best. The standard anteroposterior and lateral angiographic views are insufficient in most cases, due to overlapping of vascular structures over the neck of the aneurysm.

The complete aneurysm occlusion by GDC technique dropped to less than $45 \%$ in small aneurysms with a wide neck and in large and giant aneurysms. The utilization of soft coils and the balloon-assisted technique is already dramatically increasing the number of complete anatomical occlusion in this type of difficult aneurysms.
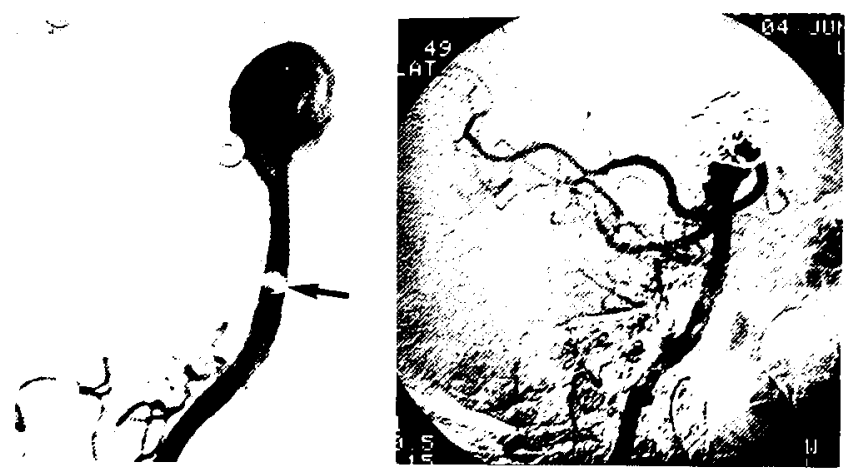

Fig. 6 Guglielmi detachable coil (GDC) embolization of giant aneurysm. Lateral vertebral angiogram (left) shows a giant basilar tip aneurysm found incidentally. A partially inflated balloon (arrow) is noted in the midbasilar trunk to control arterial flow into the aneurysm. Postembolization vertebral angiogram (right) shows partial occlusion of the dome and body of the aneurysm with GDC coils. The neck of the aneurysm involved the origin of both posterior cerebral arteries and right superior cerebellar artery. The patient had a fatal intracranial bleed 16 months postembolization.

Table 7 Angiographic follow-up

\begin{tabular}{cccc}
\hline Aneurysm & Unchanged & $\begin{array}{c}\text { Recanaliza- } \\
\text { tion }\end{array}$ & $\begin{array}{c}\text { Increased } \\
\text { thrombosis }\end{array}$ \\
\hline $\begin{array}{c}\text { Anterior circulation: } \\
\text { Small aneurysm/ } \\
\text { small neck }\end{array}$ & $93.3 \%$ & $6.7 \%$ & $0 \%$ \\
$\begin{array}{c}\text { Small aneurysm/ } \\
\text { wide neck }\end{array}$ & $71.4 \%$ & $14.4 \%$ & $14.2 \%$ \\
$\begin{array}{c}\text { Large aneurysm } \\
\text { Giant aneurysm }\end{array}$ & $58.3 \%$ & $30.7 \%$ & $11 \%$ \\
$\begin{array}{c}\text { Posterior circulation: } \\
\text { Small aneurysm/ }\end{array}$ & $43.9 \%$ & $47.4 \%$ & $8.7 \%$ \\
$\quad$ small neck & $77.7 \%$ & $6.1 \%$ & $16.2 \%$ \\
$\begin{array}{c}\text { Small aneurysm/ } \\
\text { wide neck }\end{array}$ & $37.5 \%$ & $39.17 \%$ & $12.5 \%$ \\
$\begin{array}{c}\text { Large aneurysm } \\
\text { Giant aneurysm }\end{array}$ & $42.8 \%$ & $28.5 \%$ & $28.7 \%$ \\
\hline
\end{tabular}

Table 7 shows the long-term angiographic followups in anterior and posterior circulations. Aneurysm recanalization was observed in $6 \%$ of small aneurysms with a small neck and increased in wide neck, large and giant aneurysms. The technical reason behind it is the difficulty of obtaining a tight, dense packing of GDCs in the aneurysms inflow zone in those type of aneurysms. Again, the use of soft coils and Moret's balloon-assisted technique 
will decrease recanalization rates in many of these aneurysms.

Thirteen percent of patients had a second endovascular GDC embolization, $4 \%$ had a third embolization, and $9 \%$ had a post-GDC neurosurgical intervention. Six percent of posterior circulation aneurysms required surgical clipping to obtain a complete aneurysm obliteration. This surgical procedure was done in $3 \%$ of anterior circulation aneurysms.

The presence of GDCs in an aneurysm does not preclude post-embolization surgical clipping. The partial occlusion of the body and dome of the aneurysm with GDCs facilitates the aneurysm manipulation at surgery and decreases the possibility of per-operative aneurysm rupture. The presence of GDCs across the neck of the aneurysm may hamper the position of the clip. In giant aneurysms, the presence of a mass of coils in the body of the aneurysm precludes the surgical decompression of the aneurysm and better surgical control of its neck. The decision to utilize the GDC technology in giant aneurysms should be done by exclusion and not as a primary therapeutic weapon, due to its present important technical limitations (high recanalization rate, increased mass effect, etc.).

Table 8 details immediate clinical outcome in anterior and posterior circulation aneurysms. The morbidity in posterior circulation aneurysms was slightly higher and no significant differences in mortality was depicted. A $2 \%$ immediate mortality was observed in the anterior circulation versus $2.3 \%$ in the posterior circulation. The increased morbidity-mortality in posterior circulation aneurysms reflects the increased incidence of acutely ruptured aneurysms and decreased incidence of incidental aneurysms in

Table 8 Immediate clinical outcome

\begin{tabular}{lcc}
\hline Clinical status & $\begin{array}{c}\text { Anterior } \\
\text { circulation }\end{array}$ & $\begin{array}{c}\text { Posterior } \\
\text { circulation }\end{array}$ \\
\hline Intact & $53.2 \%$ & $37.7 \%$ \\
Unchanged & $37.5 \%$ & $50 \%$ \\
Deteriorated & $7.3 \%$ & $10 \%$ \\
Death & $2 \%$ & $2.3 \%$ \\
\hline
\end{tabular}

Table 9 Most common technical complications

\begin{tabular}{lcc}
\hline \multicolumn{1}{c}{ Complication } & $\begin{array}{c}\text { Anterior } \\
\text { circulation }\end{array}$ & $\begin{array}{c}\text { Posterior } \\
\text { circulation }\end{array}$ \\
\hline Cerebral embolization & $3.5 \%$ & $1.3 \%$ \\
Parent artery occlusion & $2.6 \%$ & $2.7 \%$ \\
Aneurysm perforation & $2.4 \%$ & $3.8 \%$ \\
Artery dissection & $0 \%$ & $0.6 \%$ \\
\hline
\end{tabular}

this circulation. It does not reflect a particular technical difficulty on the GDC occlusion of posterior circulation aneurysms. The most common technical complication observed in posterior circulation aneurysms was aneurysm perforation $(3.8 \%)$. Untoward cerebral embolization $(3.5 \%)$ was the most common technical complication in the anterior circulation (Table 9). Cerebral embolization and parent artery occlusion was more common in middle cerebral artery aneurysms, due to difficulty of identifying the neck of the aneurysm in this location.

Table 10 details immediate clinical morbidity related to Hunt and Hess grading of acute subarachnoid hemorrhage. There are no substantial differences between anterior and posterior circulation aneurysms in this series. The morbidity-mortality of the GDC technology in patients presenting with Hunt and Hess grades I-III is very low. It increases in Hunt and Hess grades IV-V due to the primary brain damage produced by the intracranial hemorrhage.

Table 11 describes long-term clinical outcomes in anterior and posterior circulations. A permanent clinical deterioration was observed in $2.6 \%$ of the anterior circulation and in $6.1 \%$ of the posterior circulation aneurysms. The death rate includes $4.3 \%$ in

Table 10 Morbidity, mortality, and Hunt and Hess grading

\begin{tabular}{ccc}
\hline Grade & $\begin{array}{c}\text { Anterior } \\
\text { circulation }\end{array}$ & $\begin{array}{c}\text { Posterior } \\
\text { circulation }\end{array}$ \\
\hline Morbidity: & $6.2 \%$ & $5.4 \%$ \\
I & $5.2 \%$ & $5.1 \%$ \\
II & $9.5 \%$ & $8.1 \%$ \\
III & $7 \%$ & $11 \%$ \\
IV & $7.1 \%$ & $9 \%$ \\
V & & \\
Mortality: & $0 \%$ & $0 \%$ \\
I & $0 \%$ & $0 \%$ \\
II & $4.7 \%$ & $0 \%$ \\
III & $10.6 \%$ & $35 \%$ \\
IV & $32 \%$ & $33 \%$ \\
V & & \\
\hline
\end{tabular}

Table 11 Long-term clinical outcome

\begin{tabular}{lcc}
\hline Clinical status & $\begin{array}{c}\text { Anterior } \\
\text { circulation }\end{array}$ & $\begin{array}{c}\text { Posterior } \\
\text { circulation }\end{array}$ \\
\hline Intact & $54.3 \%$ & $32.1 \%$ \\
Improved & $12.7 \%$ & $23.6 \%$ \\
Unchanged & $12.3 \%$ & $13 \%$ \\
Deteriorated & $2.63 \%$ & $6.1 \%$ \\
Death & $4.3 \%$ & $7.5 \%$ \\
Unknown & $13.5 \%$ & $24 \%$ \\
\hline
\end{tabular}


anterior circulation and $7.5 \%$ in posterior circulation aneurysms.

The GDC embolization of intracranial aneurysms is a valuable therapeutic alternative in patients presenting with ruptured or unruptured aneurysms. This technology was first applied only in patients harboring high-risk surgical aneurysms. Its present clinical indications includes a broader spectrum of aneurysms in patients with different clinical conditions. It is particularly valuable in the acute phase of subarachnoid hemorrhage because it can be performed in very sick patients, eliminating a fatal rehemorrhage and allowing an aggressive medical/endovascular therapy of symptomatic vasospasm.

In patients with multiple aneurysms, it is possible to occlude the ruptured aneurysm and incidental aneurysms in the same procedure without increasing the technical or clinical morbidity of the procedure.

The present anatomical results are predominantly influenced by the relationship of the width of the body of the aneurysm to its neck and not by the location of the aneurysm. The utilization of a new generation soft coils and 3-D coils and the Moret's GDC balloon-assisted technique are already improving the immediate and long-term anatomical results in wide neck and large aneurysms.

GDC technique is also valuable for the embolization of incidental aneurysms in an older population. The increased depiction of unruptured aneurysms by head magnetic resonance imaging and magnetic resonance angiography in healthy patients 70 years of age or older identifies a population that does benefit from the endovascular GDC aneurysm occlusion without the need of complex general anesthesia and surgical brain manipulation.

The true place of the GDC technology in the therapeutic management of patients harboring ruptured or unruptured intracranial aneurysms will be given by a scientific, double-blinded, randomized trial comparing surgical versus GDC immediate and long-term anatomical and clinical outcomes.

\section{References}

1) Guglielmi G, Viñuela F, Dion J, Duckwiler G: Electrothrombosis of saccular aneurysms via endovascular approach. Part 2. Preliminary clinical experience. J Neurosurg 75: 8-14, 1991

2) Guglielmi G, Viñuela F, Duckwiler G, Dion J, Lylyk P, Berenstein A, Strother C, Graves V, Halbach V, Nichols D, et al: Endovascular treatment of posterior circulation aneurysms by electrothrombosis using electrically detachable coils. J Neurosurg 77: 515-524, 1992

3) Gurian JH, Vinuela F, Guglielmi G, Gobin YP, Duckwiler GR: Endovascular embolization of superior hypophyseal artery aneurysms. Neurosurgery 39: 1150-1156, 1996

4) Higashida RT, Halbach VV, Barnwell SL, Dowd C, Dormandy B, Bell J, Hieshima GB: Treatment of intracranial aneurysms with preservation of the parent vessel: Results of percutaneous balloon embolization in 84 patients. AJNR Am J Neuroradiol 11: 663-640, 1990

5) Kinugasa K, Mandai S, Terai Y, Kamata I, Sugiu K, Ohmoto $\mathrm{T}$, Nishimoto A: Direct thrombosis of aneurysms with cellulose acetate polymer. Part II: Preliminary clinical experience. J Neurosurg 77: 501507, 1992

6) Knuckey NW, Haas R, Jenkins R, Epstein MH: Thrombosis of difficult intracranial aneurysms by the endovascular placement of platinum-Dacron microcoils. J Neurosurg 77: 43-50, 1992

7) Moret J, Cognard C, Weill A, et al: The "Remodelling Technique" in the treatment of wide neck intracranial aneurysms. Angiographic results and clinical followup in 56 cases. Interventional Neuroradiology 3: 21-36, 1997

8) Vinuela F, Duckwiler G, Maead M, et al: Guglielmi detachable coil embolization of acute intracranial aneurysm: perioperative anatomical and clinical outcome in 403 patients. J Neurosurg 86: 476-482, 1997

Address reprint requests to: F. Viñuela, M.D., Division of Interventional Neuroradiology, UCLA Department of Radiological Sciences, CHS Building, Box 951721, Los Angeles, CA 90095-1721, U.S.A. 